\title{
PENDAMPINGAN PEMBUATAN MINYAK SUMBAWA PADA KARANG TARUNA DESA REMPE SETELUK SUMBAWA BARAT
}

\author{
Ibrahim 1), Mas'ad'), Junaidi A.M(1), Kamaluddin'), Siti Hasanah'), Sri Rejeki'), Muhammad Ali'), \\ Anwar Efendy 1), Mintasrihardi'), Asma Azizah'), Burhanuddin ${ }^{3)}$, Muhammad Saleh ${ }^{3)}$, \\ M. Sobry ${ }^{4)}$, Akhmad Syafruddin ${ }^{5)}$, Muhammad Salahuddin ${ }^{6)}$ \\ 1)Universitas Muhammadiyah Mataram, Mataram, NTB, Indonesia \\ 2)Universitas Pendidikan Indonesia, Bandung, Indonesia \\ ${ }^{3}$ Universitas Mataram, Mataram, NTB, Indonesia \\ 4)Universitas Islam Negeri Mataram, Mataram, NTB, Indonesia \\ 5)Universitas Nuca Cendana, Kupang, NTT, Indonesia \\ ${ }^{6}$ Universitas Samawa, Sumbawa Besar, NTB, Indonesia \\ Corresponding author :Ibrahim \\ E-mail : ibrahimali.geo@gmail.com
}

Diterima 13 Oktober 2021, Disetujui 22 Oktober 2021

\begin{abstract}
ABSTRAK
Tujuan dilakukan pengabdian kepada masyarakat khususnya Pembuatan Minyak Sumbawa (Melala) dalam rangka siar budaya dan pengenalan pada Karang Taruna Desa Rempe Seteluk Sumbawa Barat. Pengenalan pembuatan minyak Sumbawa pada generasi muda saat ini sebagai langkah memperkenalkan minyak Sumbawa sebagai Obat tradisional sebagai obat-obatan yang diolah secara tadisional, turun-temurun berdasarkan resep nenek moyang, adat-istiadat, kepercayaan dan kebiasaan setempat, sehingga merupakan pengetahuan tradisional. Pengabdian kepada masyarakat dilakukan di Desa Rempe Kecamatan Seteluk Kabuapten Sumbawa Barat. Metode yang digunakan adalah sosialisasi dan praktek langsung. Hasil Pengabdian kepada masyarakat ini diketahui bahwa antusias dari karang taruna dalam ikut terlibat dalam pembutan minyak Sumbawa cukup tinggi karena memberikan pengetahuan baru dalam mengembangkan budaya local di masa akan datang.
\end{abstract}

Kata Kunci: pendampingan; minyak sumbawa dan karang taruna.

\begin{abstract}
The purpose of doing community service, especially Sumbawa Oil Production (Malala) in the context of cultural broadcasting and introduction to the Youth Organization of Rempe Seteluk Village, West Sumbawa. The introduction of Sumbawa oil manufacture to the younger generation today is a step to introduce Sumbawa oil as traditional medicine as medicines that are processed traditionally, from generation to generation. from generation to generation based on ancestral recipes, customs, beliefs and local customs, so that it is traditional knowledge. Community service is carried out in Rempe Village, Seteluk District, West Sumbawa Regency. The method used is socialization and direct practice. The results of this community service show that the enthusiasm of youth organizations in being involved in the production of Sumbawa oil is quite high because it provides new knowledge in developing local culture in the future.
\end{abstract}

Keywords: mentoring; sumbawa oil and youth organizations.

\section{PENDAHULUAN}

Obat tradisional sebagai obat-obatan yang diolah secara tadisional, turun-temurun berdasarkan resep nenek moyang, adatistiadat, kepercayaan dan kebiasaan setempat, sehingga merupakan pengetahuan tradisional. Bagian (organ) tumbuhan yang dimanfaatkan untuk pengobatan adalah akar (radix), rimpang (rhizome), batang (caulis), buah(fructus), daun (folia) dan bunga (flos).

Sumbawa sebagai suku terbesar di Nusa Tenggara Barat memiliki keunikan dalam adat istiadat terutama berkaitan dengan minyak. Minyak sumbawa adalah salah satu obat tradisional asli Indonesia yang dapat digunakan sebagai obat luar maupun obat dalam. Minyak Sumbawa ini terbuat dari berbagai jenis tumbuhan-tumbuhan asli daerah Sumbawa Besar. Tumbuh-tumbuhan tersebut diperoleh dari pegunungan di kabupaten Sumbawa Besar. Minyak Sumbawa telah dirkenal sampai ke manca negara. Selain itu, minyak Sumbawa telah terdaftar di departemen kesehatan RI (Aduyana, 2011). Minyak Sumbawa dipercaya berkhasiat untuk mengurangi gejala rematik, 
keseleo, sakit pinggang, luka, koreng, luka bakar, sariawan, sakit gigi, digigit serangga dan meningkatkan vitalistas pria, dan mempercepat pemulihan kondisi ibu pasca persalinan. Pemanfaatan minyak sumbawa yang umum oleh masyarakat adalah mengurangi nyeri dan bengkak pada tulang, sendi dan otot, dan mempercepat penyembuhan berbagai macam luka. Cara penggunaannya dioleskan di bagian yang mengalami kelainan atau diminum untuk mendapatkan efek sistemiknya. Selain itu minyak sumbawa juga dipercaya berkhasiat sebagai peluruh angin (karminatif), pereda kejang (antispasmodik), penurun panas (antipiretik), penambah nafsu makan (stomakik) (Anggraini, 2005).

Keberadaan minyak Sumbawa memiliki pemanfaatan dalam mengembangkan adat istiadat yang sudah mendunia. Namun kondisi saat ini rendahnya kesadaran generasi muda dalam menjaga dan melestarikannya. Oleh karena itu, menjadi penting diadakan kegiatan pengabdian masyarakat ini sebagai agent support ilmu pengetahuan dari generasi tua pada generasi muda terutama karang taruna sebagai estapet jangka pangjang. Oleh karena itu kegiatan ini mengambil tema tentang Pendampingan Pembuatan Minyak Sumbawa Pada Karang Taruna Desa Rempe Seteluk Sumbawa Barat.

\section{METODE}

Pengabdian ini dilaksanakan pada tanggal 14 September 2021, Tepatnya di Desa Rempe Kecamatan Seteluk Kabupaten Sumbawa Barat.

Mitra dalam kegiatan pengabdian ini adalah Karang Taruna Desa Rempe Kecamatan Seteluk. Kegiatan ini melibatkan anggota karang taruna dan tokoh masyarakat. Kegiatan ini dihadari sebanyak 20 orang sasaran. Adapun penggagas Dr. Ibrahim, M.Sc dan menghadir Bapak Sulaiman sebagai orang tua sekaligus santro (Bahasa sumbawa).

Guna mendukung pelaksanaan kegiatan ini metode yang digunakan adalah sosialisasi dan praktek langsung. Kegiatan pengabdian ini dilakukan dengan beberapa tahapan diantaranya: 1) Persiapan tim pengabdian, dengan melakukan koordinasi dengan pihak mitra. 2) pelaksanaan, memberikan sosialisasi dan prakterk langsung terhadap cara membuat minyak sumbawa. 3) evaluasi, berupa feed back terhadap kegiatan tersebut guna memberikan manfaat pada pengabdian dan penelitian di masa akan datang.

\section{HASIL DAN PEMBAHASAN}

Kegiatan pendampingan pembuatan Minyak Sumbawa Pada Karang Taruna Desa Rempe telah dilaksanakan sesuai dengan yang direncanakan. Adapaun tahapan kegiatan sebagai berikut.

\section{Persiapan}

Persiapan kegiatan pengabdian kepada masyarakat melalui pendampingan pembuatan minyak Sumbawa pada Karang Taruna Desa Rempe Seteluk Sumbawa Barat. Persiapan kegiatan dengan koordinasi dengan pihak karang taruna dan santro (Bahasa Sumbawa). Lokasi kegiatan cukup jauh dari kampus mencapai $119 \mathrm{Km}$. dengan penyebrangan menggunakan kapal Verry.

Dalam persiapan pembuatan minyak Sumbawa dimulai dengan kegiatan memeras kelapa dan persiapan pemabakaran tempat tungku (Gambar 1). Persiapan ini dengan membagi pekerjaan setiap anggota karang taruna guna menyukseskan kegiatan pendampingan.
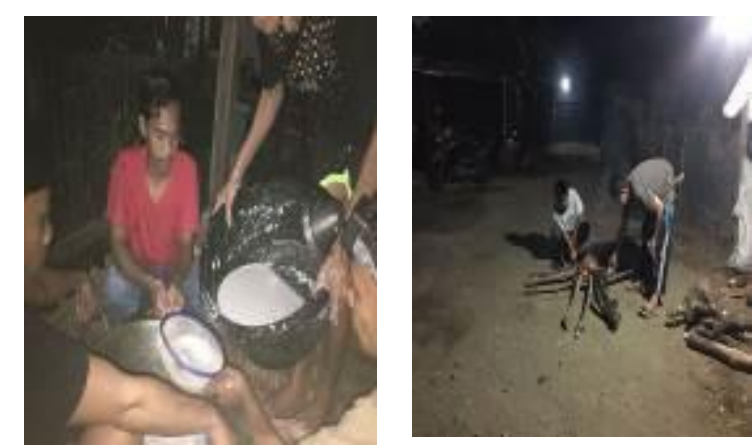

Gambar 1. Persiapan sebelum kegiatan

\section{Pelaksanaan}

Pelaksanaan kegiatan pendampingan pembuatan Minyak Sumbawa dilakukan dengan menyiapkan semua jenis kebutuhan yang diperlukan selama kegiatan. Mengingat kegiatan pembuatan minyak Sumbawa yang dikenal dengan istilah Melala. Pembuatan minyak Sumbawa ini dengan ramuan yang dimiliki oleh Sandro.

Kehidupan masyarakat Sumbawa lekat dengan budaya dan alamnya. Ini dibuktikan dengan pembuatan ramuan obat dari bahan-bahan yang alami. Tradisi Malala atau Melala adalah membuat minyak yang dijadikan obat dari bahan kelapa dan ramuan alami lainnya. Prosesi itu hanya bisa dijumpai selama bulan Muharam di tahun Hijriah.

Berbagai bahan alami digunakan seperti akar-akar kayu yang ada di dalam hutan, madu, sarang burung dan lain-lain. Terkadang seorang sandro merahasiakan bahan-bahan yang digunakannya. Berbagai akar kayu yang digunakan dan bahan alam 
sesuai dengan kebutuhan dan manfaat dari minyak tersebut. Proses pelaksanaan kegiatan dimulai pemerasan kelapa santan kelapa) menjadi bahan dasarnya yang akan menghasilkan minyak. Minyak baru bisa matang setelah sipanaskan dalam tungku berbahan bakar kayu sekitar 4 hingga 5 jam (Gambar

20).

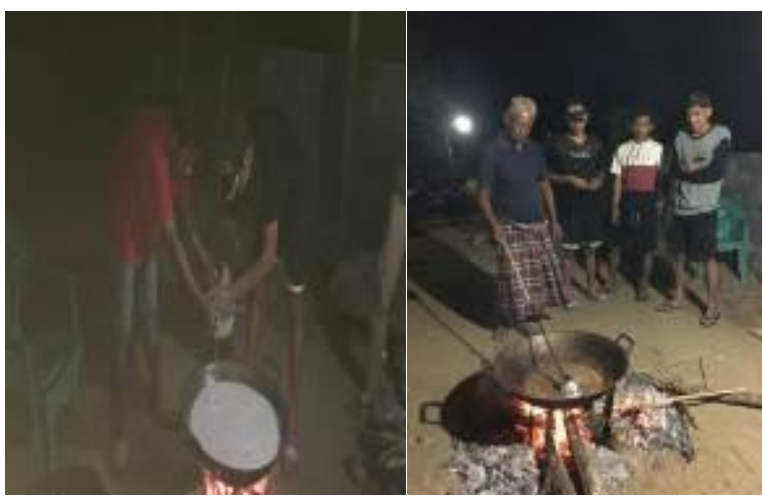

Gambar 1 Pelaksanaan Kegiatan Dengan Melibatkan Karang Taruna

Pembuatan minyak Sumbawa di bulan Muharram sebenarnya hanya prosesi saja. Tapi yang lebih sakral adalah penggunaan air hujan yang sengaja ditadah pada saat bulan Muharram. Air tersebut kemudian digunakan sebagai bahan untuk memeras santan dari kelapa untuk menghasilkan minyak.

Setelah menjadi minyak dilakukan penyaringan-pejaringann dengan berbagai fasilitas local yang dimiliki. Penjaringan ini diperlukan hanya dilakukan sebentar. Namun yang menarik dari kegiatan pembuatan minyak Sumbawa ini setelah penjaringan di adakan pencampuran antara sisa minyak dengan nasi, sehingga menjadi nasi goreng dan banyak diperrebutkan bagi masyarakat terutama generasi muda untuk mencoba memakai hasil minyak tersebut.

Pemanfaatan minyak sumbawa cukup banyak dirasakan dirasakan, terutama dalam mengurangi kolesterol. Hasil uji One Grup Pre test Post test, menggunakan 5 ekor hewan tikus b erusia dua sampai empat bulan. Setelah adaptasi selama satu minggu dan telah berhasil dibuat hiperkolesterolemia dengan telur puyuh dan larutan Propiltiourasil (PTU), dilakukan pemeriksaan pretest kadar kolesterol total. Perlakukan diberikan selama 9 hari dan dilakukan pemeriksaan kadar kolesterol total posttest. Rerata hasil pemeriksaan kadar kolesterol total pada hewan coba tikus putih ( $R$. norvegicus) strain wistar sebelum perlakuan hiperkolesterol adalah $107.80 \mathrm{mg} / \mathrm{dl}$.Rerata hasil pemeriksaan kadar kolesterol total pada hewan coba tikus putih (R. norvegicus) strain wistar setelah perlakuan hiperkolesteroladalah 148.75 $\mathrm{mg} / \mathrm{dl}$.Rerata hasil pemeriksaan kadar kolesterol total pada hewan coba tikus putih ( $R$. norvegicus) strain wistar setelah pemberian minyak Sumbawa adalah $121.75 \mathrm{mg} / \mathrm{dl}$ (Halawiya et al., 2017)

\section{Evaluasi}

Berdasarkan kegiatan pendampingan ini dengan melibatkan karang taruna. Hasil kegiatan menunjukan bahwa kegiatan memiliki kemanfaatan bagi karang taruna di masa akan datang. Hasil wawancara mendalam dengan Hasan (Anggota Karang Taruna) menujukan bahwa adanya pendampingan pembuatan minyak lala sumbawa memberikan pengetahuan baru bagi kami sebagai generasi berikut guna melestarikan budaya leluhur dimasa akan datang.

Pernyataan ini diperkuat Kakek Eman (pemangku pembuatan minyak Sumbawa) menyebutkan bahwa adanya pendampingan bagi karang taruna memberikan nilai lebih berupa pengetahuan baru dalam mengembangkan minyak sumbawa di masa depan serta hadirnya generasi muda pada kalangan karang taruna memberikan peluang dalam memperkenalkan budaya local sebagai penujang kearifal local sumbawa.

Masyarakat Sumbawa adalah suatu embodimen atau pengejawantahan nilai dan perangkat keramahtamahan (convivialisme) dalam pencapaian kehidupan harmonis antara warga dan lingkungannya melalui perwujudan nilai-nilai lokal dan praktik penghormatan terhadap penghuni lain di muka bumi agar tak musnah serta sebagai bentuk pemberdayaan pada generasi muda (Funay, 2020), (Ibrahim et al., 2018), (Suspitasari, Mas'ad, 2018).

Adanya generasi muda dalam memperkanlkan budaya local, diperlukan peran masyarakat melalui Badan Usaha Milik Desa (BUMDes) dalam memperkenalkan sebagai usaha desa sebagai asset dalam mendukung perekonomian desa. factor penghambat BUMDes pada kawasan pertambangan emas adalah 1) faktor anggaran, 2) factor Sumberdaya Manusia pengelola, dan 3) Terbatasnya dukungan dari pihak swasta,. Factor pendukung sebagai penguat adalah 1) komitmen pemerintah, dan 2) tersedianya potensi Sumber Daya Alam. Keberadaan factor penghambat karena banyak program pemerintah yang dibiayai. Diperlukan kerja keras pengelola BUMDes dalam mengembangkan usaha melalui program-program kreatif dan inovatif untuk dapat berdaya saing (Ali et al., 2019), (Ibrahim \& Sutarna, 2018), (Ibrahim et al., 2020), (Ibrahim et al., 2018) dan (Ibrahim et al., 2016). 
Kedepan diperlukan promosi dalam memperkenal kearifan local sumbawa di tingkat nasional dan internasional melalui promosi. Promosi memberikan nilai positif serta dapat menjadi mediasi antara promosi dan purchase intention (Semuel \& Setiawan, 2018), (Leonita \& Jalinus, 2018), (Zebua, 2020), (Septian \& Saputra, 2020) dan (Sulistiyawati \& Widayani, 2020).

\section{SIMPULAN DAN SARAN}

Kegiatan pendampingan pembuatan minyak Sumbawa pada karang Taruna Desa Rempe Kecamatan Seteluk memberikan dampak positif dalam mempelajari dan mengembangkan keraifan local sebagai budaya leluhur dimasa kini dan akang dating. Kedepan diperlukan event bersama dalam memperkenalkan budaya samawa ditingkat nasional dan internasional.

\section{UCAPAN TERIMAKASIH}

Kami menyampaikan terima kasih kepada Lembaga Penelitian dan Pengabdian kepada Masyarakat Universitas Muhammadiyah Mataram yang berusaha membiayai kegiatan ini dan Karang Taruna Desa Rempe Kecamatan Seteluk Kabupaten Sumbawa sebagai mitra terselengaranya kegiatan pendampingan pembuatan minyak Sumbawa.

\section{DAFTAR RUJUKAN}

Ali, I. I., Sutarna, I. T., Abdullah, I., Kamaluddin, K., \& Mas'ad, M. (2019). Faktor Penghambat Dan Pendukung Badan Usaha Milik Desa Pada Kawasan Pertambangan Emas Di Sumbawa Barat. Sosiohumaniora.

Https://Doi.Org/10.24198/Sosiohumaniora .V21i3.23464

Funay, Y. E. N. (2020). Sabalong Samalewa Sebagai Etika Moral Orang Sumbawa. Jurnal Pemikiran Sosiologi, 7(2), 103. Https://Doi.Org/10.22146/Jps.V7i2.62526

Halawiya, A., Tatontos, E. Y., \& Agrijanti. (2017). Efektivitas Sediaan Minyak Sumbawa Terhadap Kadarkolesterol Total Pada Tikus Putih (Rattusnorvegicus) Strain Wistar Yang Diberi Diet Hiperkolesterolemia. Jurnal Analis Medika Bio Sains, 4(2), 6.

Ibrahim, Baiquni, M., Ritohardoyo, S., \& Setiadi. (2016). Characteristics Of Poverty In Rural Communities Of Gold Mining District Area West Sumbawa. Mimbar, 32(1), 163-174.

Ibrahim, I., Mas,Ad, M., Kamaluddin, K., \& Djunaidi, A. (2018). Peningkatan Kualitas Pelayanan Badan Usaha Milik Desa Melalui Pelatihan Administrasi Program
Simpan Pinjam Di Selebung Batukliang Lombok Tengah. Selaparang Jurnal Pengabdian Masyarakat Berkemajuan. Https://Doi.Org/10.31764/Jpmb.V1i2.457

Ibrahim, I., \& Sutarna, I. T. (2018). Pengelolaan Badan Usaha Milik Desa Dalam Meningkatkan Kesejahteraan Masyarakat Perdesaan Kawasan Pertambangan Emas Di Kabupaten Sumbawa Barat. Tataloka. Https://Doi.Org/10.14710/Tataloka.20.3.3 09-316

Ibrahim, Mintasrihardi, Kamaluddin, Mas'ad, \& Syukuriadi. (2020). Community Empowerment Pattern Through VillageOwned Enterprise Strategy In The Gold Mine Area Of West Sumbawa, Indonesia. lop Conference Series: Earth And Environmental Science. Https://Doi.Org/10.1088/17551315/413/1/012036

Leonita, E., \& Jalinus, N. (2018). Peran Media Sosial Dalam Upaya Promosi Kesehatan: Tinjauan Literatur. Invotek: Jurnal Inovasi Vokasional Dan Teknologi, 18(2), 25-34. Https://Doi.Org/10.24036/Invotek.V18i2.2 61

Semuel, H., \& Setiawan, K. Y. (2018). Promosi Melalui Sosial Media, Brand Awareness, Purchase. Manajemen Pemasaran, 12(1), 47-52.

Septian, D., \& Saputra, A. (2020). Pengaruh Promosi Dan Kualitas Pelayanan Terhadap Kepuasan Konsumen Kepri Mall. Maker: Jurnal Manajemen, 6(1), 4353.

Https://Doi.Org/10.37403/Mjm.V6i1.151

Sulistiyawati, E. S., \& Widayani, A. (2020). Marketplace Shopee Sebagai Media Promosi Penjualan Umkm Di Kota Blitar. Jurnal Pemasaran Kompetitif, 4(1), 133. Https://Doi.Org/10.32493/Jpkpk.V4i1.7087

Suspitasari, Mas'ad, I. A. (2018). Pemberdayaan Ekonomi Masyarakat Melalui Pengembangan Kegiatan Tambak Udang Di Desa Tambak Sari Kecematan Poto Tano Kabupaten Sumbawa Barat. Geography: Jurnal Kajian Penelitian \& Pengembangan Pendidikan.

Zebua, Y. (2020). Pengaruh Budaya Kerja Dan Promosi Jabatan Dalam Meningkatkan Kinerja Karyawan Pada Pt. Perkebunan Nusantara lii Labuhan Haji Labuhanbatu Utara. Ecobisma (Jurnal Ekonomi, Bisnis Dan Manajemen), 7(2), 109-124. Https://Doi.Org/10.36987/Ecobi.V7i2.1758 